Revista de Derecho Público: Teoría y Método Marcial Pons Ediciones Jurídicas y Sociales

Vol. 1 | 2020 pp. 147-174 Madrid, 2020

DOI: 10.37417/RPD/vol_1_2020 30

(C) Nuria Magaldi

ISSN: 2695-7191

Recibido: 13/12/2019 | Aceptado: 15/01/2020

Editado bajo licencia Creative Commons Attribution 4.0 International License

\title{
EL CONCEPTO DE PROCURA EXISTENCIAL (DASEINSVORSORGE) EN ERNST FORSTHOFF Y LAS TRANSFORMACIONES DE LA ADMINISTRACIÓN PÚBLICA
}

\section{THE CONCEPT OF DASEINSVORSORGE IN ERNST FORSTHOFF AND THE TRANFORMATIONS OF PUBLIC ADMINISTRATION.}

\author{
Nuria Magaldi \\ Profesora Titular de Derecho Administrativo \\ Universidad de Córdoba
}

RESUMEN: Este artículo estudia el concepto de Daseinsvorsorge del iuspublicista alemán Ernst Forsthoff. Para ello se presentan, en primer lugar, las bases sociológicas que permitieron su teorización, a partir de las transformaciones experimentadas como consecuencia de la Revolución industrial. Seguidamente, se analiza cómo dichas transformaciones supusieron, a su vez, un cambio en el modelo de Estado liberal y de su Administración pública. Finalmente, la última parte del trabajo se dedica a los intentos realizados por el propio Forsthoff para tratar de delimitar jurídicamente los contornos de la procura existencial y atribuirle, así, significación jurídica en el marco del ordenamiento jurídico alemán.

PALABRAS CLAVE: Daseinsvorsorge; servicio público; Administración prestadora; Estado social.

ABSTRACT: This article deals with Ernst Forsthoff's concept of Daseinsvorsorge. Firstly, we will analyse the sociological background of the Daseinsvorsorge, taking into account the radical transformation of the society as a consequence of the Industrial Revolution. Secondly, we will focus on how this process led to substantial changes in the main features of the XIXth century liberal State and its Public Administration. Finally, we will discuss how Forsthoff tried to define and clarify the legal contours of the Daseinsvorsorge, in order to include it into the German legal order.

KEYWORDS: Daseinsvorsorge; public service; provider Public Administration; Social State. 
SUMARIO: 1. INTRODUCCIÓN.-2. LAS BASES SOCIOLÓGICAS DEL CONCEPTO FORSTHOFFIANO DE PROCURA EXISTENCIAL.-3. LAS TRANSFORMACIONES DEL ESTADO Y DE LA ADMINISTRACIÓN.-4. LOS CONCEPTOS JURÍDICOS DE PROCURA EXISTENCIAL (DASEINSVORSORGE), ADMINISTRACIÓN PRESTACIONAL (LEISTUNGSVERWALTUNG) Y RESPONSABILIDAD ADMINISTRATIVA SOBRE LA PROCURA EXISTENCIAL (DASEINSVERANTWORTUNG). 4.1. La construcción jurídica de la Daseinsverantwortung. 4.2. El intento de perfilar jurídicamente los contornos de la Daseinsvorsorge. 4.3. Daseinsvorsorge y principio de subsidiariedad.-5. CONCLUSIONES. -6. BIBLIOGRAFÍA

\section{INTRODUCCIÓN}

En 1938 se publicaba en Alemania un opúsculo de apenas cincuenta páginas titulado Die Verwaltung als Leistungsträger. Su autor era el por entonces joven catedrático de la Universidad de Königsberg, Ernst Forsthoff. El trabajo no tuvo, en el momento de su publicación, especial repercusión, pasando más bien inadvertido. Sin embargo, pocos años después se erigió en una obra de referencia, hasta el punto de que en 1959 se habían agotado los ejemplares disponibles. Por este motivo el propio autor, consciente de la especial significación que aquel trabajo había adquirido para la dogmática del Derecho administrativo, accedió a la reedición del texto original, con la intención de volver a hacerlo accesible al público ${ }^{1}$. Se publicó así su monografía Cuestiones jurídicas de la Administración prestadora (Rechtsfragen der leistenden Verwaltung), en realidad un compendio de artículos procedentes de momentos distintos: junto a los capítulos más importantes de aquel trabajo de 1938, reproducidos íntegramente y sin modificación respecto del original, se incluyeron otros dos artículos sobre el mismo tema -la procura existencial- escritos a finales de los años cincuenta. Su análisis constituirá el grueso del presente trabajo.

Nacido en 1902 en el seno de una familia protestante, Ernst Forsthoff fue uno de los discípulos más importantes e influyentes del siempre polémico Carl Schmitt, figura a la que se le vincula irremediablemente ${ }^{2}$. Como buena parte de la doctrina

\footnotetext{
1 Cfr. al respecto el breve prólogo a dicha reedición en Ernst FORSTHOFF, "Vorwort", en Ernst FORSTHOFF, Rechtsfragen der leistenden Verwaltung, W. Kohlhammer Verlag, Stuttgart, 1959.

2 En efecto, FORSTHOFF permaneció ligado a la figura de su maestro durante toda su vida, salvo un periodo de una década coincidente con los años inmediatamente previos a la guerra y durante la misma, en el que se distanció de aquel por su posicionamiento abiertamente antisemita. A partir de 1948, no obstante, retomaron el contacto, que ya nunca volverían a perder. Conocidos son, en este sentido, los seminarios de Ebrach y la publicación, hace algunos años, de la relación epistolar entre ambos autores. Cfr. Angela REINTHAL/Reinhard MUSSGNUG/Dorothee MUSSGNUG (eds.), Briefwechsel Ernst Forsthoff-Carl Schmitt (1926-1974), Akademie Verlag, Berlin, 2007. En relación con dicha correspondencia véase también, en lengua castellana, Francisco SOSA WAGNER, Carl Schmitt y Ernst Forsthoff: coincidencias y confidencias, Marcial Pons, Madrid-Barcelona-Buenos Aires, 2008. Sobre los Ebracher Seminare cfr. las interesantes consideraciones de Esteve Pardo en su reciente monografía José ESTEVE PARDO, El pensamiento antiparlamentario y la formación del Derecho público en Europa, Marcial Pons, Madrid-Barcelona- Buenos Aires-Sao Paulo, 2019, pp. 61 y 174-175.
} 
alemana de la época, también Forsthoff mostró en sus inicios una cierta fascinación por el nacionalsocialismo (recuérdense en este sentido las dos ediciones de su Der totale Staat), lo que jamás le fue perdonado en la Alemania de la posguerra, a pesar de haber tratado de distanciarse expresamente de dicho periodo ${ }^{3}$. No obstante, tampoco cabe catalogarlo propiamente entre aquellos autores abierta y claramente posicionados con la doctrina nacionalsocialista ${ }^{4}$.

Lo cierto es que, como ocurre con muchos de los iuspublicistas alemanes activos durante el convulso periodo de entreguerras y de la República de Weimar, la figura de Forsthoff es una figura poliédrica y compleja y, aún a día de hoy, controvertida. Existen numerosas y muy diversas posiciones doctrinales en torno a la figura y la obra forsthoffiana; no pocas de ellas, profundamente críticas. Así, se le ha considerado un continuador de las reflexiones de Schmitt pero en el marco de las democracias industriales avanzadas ${ }^{5}$, un representante del conservadurismo reformador ${ }^{6}$ o un conservador autoritario y radical que únicamente aceptó el parlamentarismo democrático por la fuerza de los hechos 7 . En lo que, en todo caso, sí parece existir acuerdo es en que se trata de un autor clave en la doctrina jurídica alemana del periodo central del siglo $\mathrm{xx}^{8}$.

3 Cfr. Hans Hugo KLEIN, "Der totale Staat. Betrachtungen zu Ernst Forsthoffs gleichnamiger Schrift von 1933", en Willi BLÜMEL (ed.), Ernst Forsthoff: Kolloquium aus Anlass des 100. Geburtstags von Porf. Dr. H.c. Ernst Forsthoff, Wissenschaftliche Abhandlungen und Reden zur Philosophie, Politik und Gesitesgeschichte, Band 30, Duncker \& Humblot, Berlín, 2003, pp. 21-33 (p. 32). Poniendo en duda el distanciamiento real respecto del nacionalsocialismo, Peter CALDWELL, "Ernst Forsthoff and the legacy of radical conservative State Theory in the Federal Republic of Germany", History of Political thought, vol XV, núm. 4, 1994, pp. 614-641 (pp. 628-630).

4 En este sentido, DREIER encuadra la figura de FORSTHOFF en aquel grupo de autores alemanes que, sin declararse explícitamente seguidores del (ni afiliarse al) nacionalsocialismo, sí se posicionaron del lado del nuevo sistema, al menos en sus inicios, no optando pues, ni por el exilio (forzado o voluntario) ni por el retiro interior. En cualquier caso, y al menos para FORSTHOFF, "la fascinación no duró mucho". Cfr. Horst DREIER, "Die deutsche Staatsrechtslehre in der Zeit des Nationalsozialismus", en AAVV, Die deutsche Staatsrechtslehre in der Zeit des Nationalsozialismus, Veröffentlichungen der Vereinigung der Deutschen Staatsrechtslehrer núm. 60, Walter de Gruyter, Berlín-Nueva York, 2001, pp. 9-69 (p. 17). Por su parte, SORDI lo califica como un jurista próximo al régimen, pero "más generacional que orgánicamente". Cfr. Bernardo SORDI, "Il primo e l'ultimo Forsthoff", Quaderni fiorentini 25, Giuffrè, Milán, 1996, pp. 667-682, (p. 670).

5 Alessandro MANGIA, "Introduzione", en Alessandro MANGIA, L'ultimo Forsthoff. Scritti 1961/1969 di E. Forsthoff su Costituzione ed amministrazione tradotti e commentati, Cedam, Milán, 1995, pp. 3-38 (p. 3), siguiendo a ORTINO.

6 Dirk van LAAK, Gespräche in der Sicherheit des Schwiegens. Carl Schmitt in der politischen Geistegeschichte der frühen Bundesrepublik, Akademie Verlag, Berlín, 1993, p. 246. Años más tarde SCHÜTTE hablaría, en términos similares, de un reformismo administrativo sobre la base de un profundo conservadurismo. Cfr. el expresivo título de su monografía Progressive Verwaltungsrechtswissenschaft auf konservativer Grundlage: Zur Verwaltunsrechtslehre Ernst Forsthoffs, Dunker \& Humblot, Berlín, 2006.

7 Peter CALDWELL, "Ernst Forsthoff and the legacy of radical conservative State Theory in the Federal Republic of Germany", op. cit., p. 630.

8 Así lo reconocen, entre otros, Dirk VAN LAAK, Gespräche in der Sicherheit des Schwiegens. Carl Schmitt in der politischen Geistegeschichte der frühen Bundesrepublik, op. cit., p. 244; Alessandro MANGIA, L'ultimo Forsthoff. Scritti 1961/1969 di E.Forsthoff su Costituzione ed amministrazione tradotti 
El presente trabajo pretende ser un acercamiento a la que es, sin género de dudas, su aportación más conocida y celebrada: la Daseinsvorsorge o procura existencial, teorizada en escasamente medio centenar de páginas en el mencionado opúsculo de 1938. En este sentido, Die Verwaltung als Leistungsträger está considerado como el trabajo que sienta las bases teóricas de la Administración prestadora en Alemania. Es más, en la prestigiosa reunión anual de profesores alemanes del año 2000, dedicada precisamente a los juristas alemanes del nacionalsocialismo, Forsthoff es mencionado no por su posicionamiento político e ideológico sino por ser el creador "de uno de los pocos avances que la doctrina de aquel momento fue capaz de legar a la ciencia jurídica" ${ }^{9}$. Esta afirmación da idea, pues, de la relevancia y significación de su trabajo Die Verwaltung als Leistungsträger, comparable, en cierto modo, a Les transformations du droit publique de Léon Duguit, con quien comparte más similitudes de las que en un primer momento cabría pensar.

La obra forsthoffiana va, en cualquier caso, más allá de la teorización de la procura existencial, no limitándose exclusivamente a cuestiones de Derecho administrativo. Por el contrario, se trata de una obra extensa y variada, que abarca temas muy diversos, propios tanto del Derecho administrativo como del Derecho constitucional. Forsthoff fue, en este sentido, un auténtico iuspublicista.

Desde luego, fue un influyente administrativista, tal y como demuestra el éxito de su Lehrbuch des Verwaltungsrechts (Tratado de Derecho administrativo), cuya primera edición vio la luz en 1950 y que posteriormente sería reeditado hasta en diez ocasiones. Después de los primeros años de la posguerra, en los que fue apartado del ejercicio de la docencia por su pasado nacionalsocialista (se le impidió el reintegro en su cátedra de la Universidad de Heidelberg), la publicación del Tratado le colocó de nuevo en primera línea de la doctrina iuspublicista alemana ${ }^{10}$, proporcionándole

e commentati, op. cit., nota bibliografica, p. 5; Hans SCHNEIDER, "Ernst Forsthoff. Berichte", Die Öffentliche Verwaltung, núm. 17, 1974, p. 596; Bernardo SORDI, "Il primo e l'ultimo Forsthoff", op. cit., p. 669; Peter HÄBERLE, "Lebende Verwaltung trotz überlebter Verfassung? Zum wissenschaftlichen Werk von Ernst Forsthoff", en Peter HÄBERLE, Beiträge zur Staatsrechtslehre und Verfassungskultur, Duncker \& Humblot, Berlín, 2002, p. 3 y 11-13. Incluso Peter CALDWELL, uno de los autores contemporáneos más críticos con FORSTHOFF, afirma que dejó una "profunda huella en la vida intelectual y cultural de la República Federal". Cfr. Peter CALDWELL, "Ernst Forsthoff and the legacy of radical conservative State Theory in the Federal Republic of Germany", op. cit., p. 615.

9 Léase al respecto la transcripción del debate que siguió a las ponencias de DREIER y PAULY y, en particular, las intervenciones de BÖCKENFÖRDE y HOLLERBACH, para quienes el concepto de procura existencial debe ser considerado como uno de los grandes logros de esa época. Cfr. AAVV, "Aussprache und Schlussworte", en AAVV, Die deutsche Staatsrechtslehre in der Zeit des Nationalsozialismus, Veröffentlichungen der Vereinigung der Deutschen Staatsrechtslehrer núm. 60, Walter de Gruyter, Berlín-Nueva York, 2001, pp. 106-147 (pp. 126 y 133). El mismo PAULY, en su ponencia, se refería a dicho concepto como "un avance de deslumbrante carácter". Cfr. Wolfgang PAULY, "Die deutsche Staatsrechtslehre in der Zeit des Nationalsozialismus", en AAVV, Die deutsche Staatsrechtslehre in der Zeit des Nationalsozialismus, op. cit., pp. 73-101 (pp. 97-99).

10 Así, señala quien fuera uno de sus discípulos, Karl DOEHRING, que en 1951 el decano de la Facultad de Heidelberg y prestigioso filósofo del Derecho, ENGISCH, lo presentó ante los estudiantes como "uno de los más significativos iuspublicistas del momento". Cfr. Karl DOEHRING, "Enrst 
también prestigio en el ámbito internacional, con traducciones a varios idiomas, entre ellos el castellano ${ }^{11}$. Como el propio Forsthoff señaló en su momento, el Tratado recogía y partía, en buena medida, de las reflexiones que había plasmado en su momento en su trabajo seminal de 1938 sobre la Daseinsvorsorge.

Sin embargo, sería incompleto limitar la obra científica de Forsthoff al Derecho administrativo. Su importante contribución al Derecho constitucional a través, fundamentalmente, de un conjunto de escritos recogidos posteriormente en Estado de Derecho en transformación (Rechtsstaat im Wandel, 1964) y en El Estado de la sociedad industrial (Staat der Industriegesellschaft, 1971), en los que analizó cuestiones relativas a la interpretación constitucional y a la (in)compatibilidad constitucional entre Estado de Derecho y Estado social está fuera de toda duda. Y ello, a pesar de que defendiera una posición minoritaria en la doctrina y enfrentada al Tribunal Constitucional alemán en aspectos esenciales como, entre otros, la cláusula del Estado social contenida en la Ley Fundamental de Bonn o la eficacia de los derechos fundamentales ${ }^{12}$.

La amplitud y la magnitud de las reflexiones de Forsthoff en torno a las cuestiones nucleares del Derecho público del siglo xx -se compartan o no- obligan necesariamente a una contemplación y análisis de su Daseinsvorsorge desde el conocimiento y la consideración de todo el conjunto de su producción científica. De otro modo se corre el riesgo de caer en una valoración estereotipada de dicho autor, como ha señalado con acierto Mangia, sin duda uno de los mejores conocedores de su obra en Italia ${ }^{13}$.

Es, por lo tanto, desde esta amplia perspectiva desde la que pretendemos abordar el estudio de la Daseinsvorsorge forsthoffiana. Para ello partiremos, como no puede ser de otro modo, de las profundas transformaciones sociales y económicas que tuvieron lugar a partir de la segunda mitad del siglo XIx y que marcaron el tránsito del Estado liberal al Estado social de Derecho. Sin esta consideración, es imposible explicar satisfactoriamente por qué se teorizan unas nuevas funciones estatales consistentes en la garantía de la participación del individuo en las prestaciones del Estado. El análisis

Forsthoff als Hochschullerhrer, Kollege und Freund", en Willi BLÜMEL, (ed.) Ernst Forsthoff: Kolloquium aus Anlass des 100. Geburtstags von Porf. Dr. H.c. Ernst Forsthoff, Wissenschaftliche Abhandlungen und Reden zur Philosophie, Politik und Gesitesgeschichte, Band 30, Ducker \& Humblot, Berlín, 2003, pp.9-20 (pp. 9 y 10).

${ }^{11}$ La traducción del Lehrbuch al castellano fue realizada por los profesores LEGAZ LACAMBRA, GARRIDO FALLA y GÓMEZ DE ORTEGA y JUNGE en 1958. Cfr. Ernst FORSTHOFF, Tratado de Derecho administrativo, Instituto de Estudios Políticos, Madrid, 1958.

12 Cfr. con detalle sobre ello mi trabajo Nuria MAGALDI, Procura existencial, Estado de Derecho y Estado Social, Serie de teoría jurídica y filosofía del derecho núm. 48, Universidad del Externado, Bogotá, 2007, pp. 104-145.

13 Alessandro MANGIA, "Introduzione”, op. cit., p. 3; en sentido similar también Bernardo SORDI, "Il primo e l'ultimo... ", op. cit., p. 676. En Alemania han sostenido esta posición también Florian MEINEL, "Review Essay -Ernst Forsthoff and the intellectual History of German Administrative Law", German Law Journal, vol. 8, num. 8, 2007, pp. 785-800 (p. 790) y Jens KERSTEN, "Die Entwiklung des Konzepts der Daseinsvorsorge im Werk von Enst Forsthoff”, Der Staat vol. 44 num. 4 (2005), pp. 543-569 (p. 543). 
del sustrato sociológico de la procura existencial nos permitirá, a su vez, adentrarnos en los cambios que este implicó en el modelo y la concepción del Estado y de la Administración pública. Por último, trataremos de concretar los contornos jurídicos del concepto de Daseinsvorsorge y su ámbito material. Vaya por delante la dificultad de dicha tarea, especialmente por lo que se refiere a este último aspecto ${ }^{14}$. Algo de lo que, por cierto, siempre fue consciente el propio Forsthoff.

\section{LAS BASES SOCIOLÓGICAS DEL CONCEPTO FORSTHOFFIANO DE PROCURA EXISTENCIAL}

La aparición del concepto de Daseinsvorsorge o procura existencial en la obra de Ernst Forsthoff es, en buena medida, el resultado de su aguda capacidad de observación de las transformaciones políticas y sociales de su época. Si en algo hay acuerdo en torno a la controvertida figura de este autor es, precisamente, en señalar dicha capacidad como una de sus mayores virtudes y uno de los elementos que más y mejor caracterizan el conjunto de toda su obra ${ }^{15}$.

Quizás -o precisamente- por ello, lo cierto es que cabe hablar de un concepto sociológico de procura existencial, construido a partir de la observación directa de las transformaciones sociales que Alemania (y buena parte de Europa, en realidad) experimentó a partir de la segunda mitad del siglo xix y durante las primeras décadas del siglo Xx. Este concepto sociológico, prejurídico si se prefiere, conformará el sustrato sobre el que luego el propio autor tratará de construir un concepto jurídico de procura existencial y lo insertará en una renovada dogmática del Derecho administrativo, como habremos de ver.

El punto de partida de las reflexiones de Forsthoff lo constituye la Revolución industrial y los cambios que esta conllevó. En efecto, la Revolución industrial y la aparición de la paradigmática máquina de vapor de Watts supusieron un punto de inflexión en la historia, dando el pistoletazo de salida para un conjunto de profundas transformaciones sociales, económicas y políticas. Es bien conocido cómo la Revolución industrial supuso el desarrollo de centros fabriles que se ubicaron, lógicamente, en los núcleos urbanos, dando lugar a un éxodo rural como no se había conocido hasta entonces ${ }^{16}$.

${ }^{14}$ Lo ha advertido en su monografía Christian SCHÜTTE, Progressive Verwaltungsrechtswissenschaft auf konservativer Grundlage: Zur Verwaltunsrechtslehre Ernst Forsthoffs, op. cit., p. 106.

15 Karl DOEHRING, "Ernst Forsthoff", en AAVV, Juristen im Portrait. Verlag und Autoren in 4 Jahrzenten: Festschrift zum 225 Jährigen Jubiläum des Verlages, C. H. Beck, Múnich, 1988, p. 341, quien destaca también la profunda consideración por la historia como otro de los grandes pilares sobre los que se asienta la obra de FORSTHOFF. En sentido similar, SCHNEIDER ha señalado que los análisis forsthoffianos trascienden el ámbito estricto del Derecho positivo, mostrando un jurista capaz de extender su mirada al conjunto de las ciencias sociales y a la realidad social y política en cuanto tal. Cfr. Hans SCHNEIDER, "Ernst Forsthoff. Berichte", op. cit., p. 597.

16 He analizado con detalle este proceso en el ámbito local y cómo permite explicar, en gran medida, el tránsito del Estado liberal de Derecho al Estado social en Nuria MAGALDI, Los orígenes de la 
Se produce así un fenómeno de aglomeración urbana que Forsthoff describe con brillantez: la gente se concentra en las ciudades -en ellas está el trabajo-, y se concentra en las fábricas -donde desarrolla largas jornadas laborales- y, finalmente, se concentra también en sus casas, cada vez más pequeñas, para con ello hacer frente al crecimiento de los núcleos urbanos. Desde una perspectiva estrictamente sociológica, como apunta Forsthoff, se produce un cambio esencial en la forma de vida del individuo. No se trata solo de que este pase a ser, masivamente, un ser urbano (frente a la ruralidad que caracterizaba al ser humano en el periodo pre-Revolución industrial) sino que, además, y como consecuencia de ello, se achica el espacio que el individuo siente como propio y se agranda, por el contrario, el espacio en el que el individuo efectivamente desempeña su existencia, su espacio vital. En efecto, antes de la Revolución industrial dicho espacio vital del individuo era, sin duda, relativamente pequeño: entre otras razones, porque no había posibilidades de trasladarse rápidamente de unos lugares a otros. Sin embargo, el individuo sentía que dominaba ese espacio en el que transcurría su vida (la granja, la finca): de él obtenía los abastecimientos básicos que necesitaba para vivir (el ejemplo paradigmático es el acceso al agua, que el campesino obtenía de su pozo), sin requerir del poder público más que el respeto a su esfera de libertad.

Forsthoff ideará un par conceptual que ilustra cómo se produce esa modificación en el entorno vital de las personas y en las formas en que se desarrollan las relaciones sociales. Así, denominará espacio vital dominado (beherrschter Lebensraum) al espacio sobre el que el individuo puede ejercer un verdadero dominio o control de su vida, mientras que el espacio vital efectivo (effektiver Lebensraum) será el espacio en el que la vida del individuo se cumple y realiza efectivamente. La Revolución industrial genera, así, lo que Forsthoff llama "modo de vida de ámbito dilatado": mientras se reduce el espacio vital dominado del individuo, al mismo tiempo se aumenta o expande su ámbito vital efectivo ${ }^{17}$.

Este fenómeno de achicamiento del espacio vital dominado tiene como consecuencia más importante el aumento de la dependencia del individuo, que ya no puede proveerse a sí mismo de los bienes y abastecimientos que necesita, sino que deberá hacerlo desde fuera, relacionándose con otros sujetos. Siguiendo con el ejemplo utilizado algunos párrafos más arriba: el hombre de la Revolución industrial, que ya no puede abastecerse del agua que extrae de su pozo, pasa a depender de un suministro de agua de carácter público, debiendo confiarse a tal efecto a una instalación pública de la Administración. Se abre así una brecha entre el espacio vital dominado y el espacio vital efectivo ${ }^{18}$. Cuanto mayor es el espacio vital dominado, mayor es

municipalización de servicios en España, Instituto Nacional de Administración Pública, Madrid, 2012, especialmente, pp. 27-34.

${ }_{17}$ Con detalle Ernst FORSTHOFF, "Die Daseinsvorsorge als Aufgabe der modernen Verwaltung”, en Ernst FORSTHOFF, Rechtsfragen der leistenden Verwaltung, W. Kohlhammer Verlag, Stuttgart, 1959 [1938], pp. 22-34 (pp. 24 y ss).

18 Ernst FORSTHOFF, "Die Daseinsvorsorge als Aufgabe der modernen Verwaltung", op. cit., p. 25 , advirtiendo además que dicha brecha iría agrandándose progresivamente con el inevitable desarrollo industrial y tecnológico. 
la existencia independente del hombre, pues en dicho espacio es capaz de hallar los abastecimientos necesarios para llevar una existencia relativamente asegurada. Por el contrario, si el espacio vital se reduce, la dependencia del individuo aumenta.

La incapacidad del individuo de la sociedad industrial de proveerse de todos los abastecimientos vitales mediante la utilización de cosas propias genera lo que Forsthoff denominó "necesidad social" (soziale Bedürftigkeit): aquella situación en la que se halla quien debe proveerse de los abastecimientos vitales no por medio de la utilización de cosas propias (de las que carece), sino por medio de la "apropiación" (Appropiation), término que tomará expresamente de Weber ${ }^{19}$.

Nótese, en este sentido, que la soziale Bedürftigkeit a que se refiere Forsthoff no se identifica con la beneficencia o asistencia social, y en ello radica la novedad, casi revolucionaria, de su planteamiento. En efecto, la soziale Bedürftigkeit nada tiene que ver con la posición económica del individuo sino con su nueva forma de vida en la ciudad, de manera que todos los individuos de los núcleos urbanos sin excepción, sean ricos o pobres, pasan a encontrarse en dicha situación. Así, todos ellos necesitarán apropiarse de bienes que no pueden conseguir por sí solos: todos ellos necesitarán de la instalación pública de la Administración para abastecerse de agua potable. Se trata de los típicos servicios de la "ciudad moderna" a que aludía en España Adolfo Posada ${ }^{20}$ : además del abastecimiento de agua potable, el alcantarillado, el alumbrado o el teléfono, entre otros. Por ello, la asistencia y beneficencia social se incluyen en el concepto de procura existencial, pero ni remotamente lo agotan ${ }^{21}$.

Las reflexiones sociológicas de Forsthoff arriba transcritas ofrecen un innegable paralelismo con el pensamiento sociológico del profesor francés Léon Duguit, plasmado en su conocida obra Les transformations du Droit publique, publicada en 1913. Un paralelismo sobre el que, salvo alguna excepción, no parece haberse insistido demasiado (y ello, a pesar de que el propio Forsthoff cita a Duguit en repetidas ocasiones) ${ }^{22}$. Lo cierto es que ambos fueron agudos observadores de una realidad

19 Ernst FORSTHOFF, "Die Daseinsvorsorge als Aufgabe der modernen Verwaltung”, op. cit., p. 26.

20 Véase, por todos, su emblemático trabajo "La ciudad moderna", en Adolfo POSADA, Escritos municipalistas de la vida local, Instituto de Administración Pública, Madrid, 1979 [1913], pp. 317-409.

21 Cfr. al respecto Ernst FORSTHOFF, "Folgerungen", en Ernst FORSTHOFF, Rechtsfragen der leistenden Verwaltung, op. cit., pp. 35-46 (p. 43).

22 Cfr. Martin BULLINGER, "El service publique francés y la Daseinvorsorge alemana", Revista de Administración Pública núm. 166 (2005), pp. 29-49, (particularmente pp. 33 y 34). En su trabajo este autor señala, ciertamente, las diferencias dogmáticas e históricas entre ambas concepciones, consecuencia sin duda de una tradición estatal diferente y de una evolución jurídica posterior también distinta. No obstante, destaca igualmente las conexiones existentes entre ambos autores, que en buena medida se basan en haber bebido de fuentes sociológicas y de una profunda consideración por la observación de la realidad. Entre nosotros también había llamado la atención sobre el paralelismo entre FORSTHOFF y DUGUIT Elisenda MALARET I GARCIA, "Servicios públicos, funciones públicas, garantía de los derechos de los ciudadanos: perennidad de las necesidades, transformación del contexto", Revista de Administración Pública núm. 145 (1998), pp. 49-88 (p. 54, nota a pie 18). Cfr. al respecto también Nuria MAGALDI, Procura existencial, Estado de Derecho y Estado Social, op. cit., pp. 74-77. 
cambiante -y en ocasiones convulsa-; supieron captarla y trataron de deducir de ella consecuencias de las que derivaron, después, categorías jurídicas que, aunque profundamente modificadas, perduran hasta hoy. Así, recuérdese cómo el propio Duguit llamaba la atención sobre el hecho de que "el pequeño grupo familiar no puede asegurar la satisfacción de las necesidades humanas", pues "ya está lejos el tiempo en que cada uno transportaba su persona y sus cosas por sus propios medios". Y ello porque, como consecuencia de "los descubrimientos científicos y de los progresos industriales, las relaciones entre los hombres han llegado a ser tan complejas y tan numerosas, y tan íntima la interdependencia social" que si las "necesidades de primordial importancia, como, por ejemplo, las relaciones postales, los transportes, el alumbrado, cuya satisfacción está asegurada por organismos vastos y muy complejos" dejaran de ser satisfechas, se generaría "una perturbación profunda que pondría en peligro la vida social misma” ${ }^{23}$.

\section{LAS TRANSFORMACIONES DEL ESTADO Y DE LA ADMINISTRACIÓN}

El alcance de los cambios sociológicos descritos es, para Forsthoff (como también para Duguit), de tal magnitud que impacta directamente a la línea de flotación del Estado liberal de Derecho característico del siglo XIX, exigiendo cambios fundamentales en su estructura y en las tareas que tiene encomendadas. Se gesta así una auténtica transformación del modelo de Estado.

Recuérdese, como indicaba el propio Forsthoff, que el Estado liberal de Derecho surgido de las Revoluciones de finales del siglo XVIII y principios del siglo XIX encumbra la garantía de la libertad (y la propiedad) del individuo frente al Estado; garantía que se consigue mediante el sometimiento de la Administración a la Ley ${ }^{24}$. Así, el individuo del Estado liberal de Derecho es un individuo que vive en una sociedad autónoma y autorregulada, en la que se siente protegido y en la que puede procurarse su propio bienestar, precisamente porque el Estado garantiza el respeto a ciertas esferas de libertad y le protege frente a la arbitrariedad y a las injerencias injustificadas en dichas esferas.

Por el contrario, las transformaciones sociales de la segunda mitad del siglo XIX colocan al individuo en una situación radicalmente diferente: este ya no puede afirmarse y realizarse por medio de la garantía de su libertad individual, sino a través de

${ }^{23}$ Léon DUGUIT, Las transformaciones del Derecho Público, Imprenta F. Beltrán, Madrid, 1926 (traducción con estudio preliminar de Adolfo POSADA y Ramón JAÉN), pp. 44-46 y 103. En el "Estudio introductorio" a la obra de DUGUIT, Adolfo POSADA ya hacía especial énfasis en esta idea afirmando que "de la tierra a la fábrica, a la mina, al taller; del campo a la ciudad; del señor al capitalista y al proletariado, [se producen] como una condición y como un resultado, una asombrosa complicación de la vida, un aumento prodigioso de las necesidades, con la consiguiente renovación y ensanchamiento de las estructuras", p. 13.

${ }^{24}$ Ernst FORSTHOFF, “Die Daseinsvorsorge als Aufgabe der modernen Verwaltung”, op. cit., p. 22. 
la apropiación. Y esta apropiación supone la participación en las prestaciones de la Administración pública. El aseguramiento jurídico de dicha participación es, precisamente, lo que permite eliminar los riesgos generados por el desarrollo de la forma de vida urbana ${ }^{25}$. Cambian, pues, los pilares sobre los que se sustentaba el Estado liberal del siglo XIX. La garantía de libertad y de propiedad, los reductos de libertad negativa frente al Estado, ya no son suficientes, aunque sigan siendo necesarios. Como señalará Forsthoff, los cambios en las formas de vida del individuo conllevan que a lo primero que haya que prestar atención es a las condiciones en las que los individuos desarrollan su existencia y, solo después, preguntarse lo que hacen con ella y cuáles son sus exigencias de libertad, orden o bienestar ${ }^{26}$. Como veremos más adelante, esta idea también encierra en sí misma un peligro para el individuo, pues puede conducir a la infravaloración (y puesta en riesgo) de las libertades individuales.

En cualquier caso, en este pensamiento forsthoffiano late, en realidad, la misma constatación que, pocos años antes, haría también Duguit en Francia. En efecto, el profesor de Burdeos observó también cómo los procesos de urbanización e industrialización conducían a que a los poderes públicos se les exigiera no ya solo hacer frente a los servicios de guerra, policía o justicia, sino a otros muchos y muy variados servicios, "de los cuales muchos tienen carácter industrial", por lo que se imponía la necesidad de un sistema de Derecho público "que dé un fundamento y una sanción a esta obligación positiva. Pero en este respecto el sistema fundado sobre la noción de soberanía adolece inevitablemente de una impotencia irremisible" 27.

Tanto Forsthoff como Duguit, pues, constatarán la incapacidad del sistema tradicional-liberal de hacer frente a la nueva realidad y tratarán de construir un sistema que dé forma jurídica a las nuevas obligaciones que se imponen a los poderes públicos y a las nuevas tareas que incumben a la Administración del siglo xx. Esas nuevas obligaciones se identificarán con el contenido de los servicios públicos en el caso de Duguit y con las prestaciones de Daseinsvorsorge, en el caso de Forsthoff.

En efecto, Duguit tratará de construir un nuevo modelo de Estado que basará, no en la noción de soberanía (hasta hace bien poco - afirmaba- la "base de las instituciones jurídicas" ${ }^{28}$ ) sino en el concepto de servicio público: "En este nuevo sistema que debe construirse, en todos esos servicios modernos, que cada día toman mayor extensión (instrucción, asistencia, obras públicas, alumbrado, correos, telégrafos, teléfonos, ferrocarriles, etc,) hay una intervención del Estado que debe estar sometida al derecho, regulada y disciplinada por un sistema de Derecho público. Pero este sistema no puede estar fundado en el concepto de soberanía, porque se aplica a actos en los que no se advierte ningún rasgo de poder de mando. Se construye pues, forzosamente un nuevo sistema, relacionado con el anterior pero fundado en una noción

\footnotetext{
25 Ernst FORSTHOFF, "Folgerungen“, op. cit., pp. 35-42.

26 Ernst FORSTHOFF, “Die Daseinsvorsorge als Aufgabe der modernen Verwaltung”, op. cit., p. 29.

27 Léon DUGUIT, Las transformaciones del Derecho Público, op. cit., pp. 82-86.

28 Léon DUGUIT, Las transformaciones del Derecho Público, op. cit., p. 39.
} 
diferente" ${ }^{29}$. El gobernante se legitima solo y únicamente en la medida en que es capaz de prestar al ciudadano servicios públicos. De este modo, el concepto de servicio público - definido de forma tan amplia que prácticamente se identifica con toda la actividad estatal- pasa a ser la noción fundamental del Derecho público moderno, en sustitución precisamente de la noción de soberanía.

Forsthoff, por su parte, criticará duramente la incapacidad de la doctrina iusdministrativista alemana para ajustarse a la realidad social de la época (por 1938, año de la primera publicación de Die Verwaltung als Leistungsträger). En su opinion, de la observación de dicha realidad social se desprende que las categorías jurídicas del Derecho público del Estado liberal no solo no permiten entender las transformaciones sociales que se estaban experimentando, sino que tampoco sirven para regularlas ${ }^{30}$. Ahora bien, Forsthoff -a diferencia de Duguit- no pondrá en duda las bases conceptuales y dogmáticas del Estado tal y como este se había construido por la doctrina alemana clásica. De hecho, afirmará expresamente que no pretende sustituir el Derecho administrativo propio del Estado liberal ni a su Administración, sino completarlos, al entender que la dogmática liberal propia de aquel Estado (y de su Administración) no agota, por sí sola, todo su objeto. Este debe contemplar también la importante tarea de proveer al individuo de aquellos bienes y prestaciones que son necesarios para su subsistencia en condiciones adecuadas; tarea que necesariamente corresponde a la Administración pública en los Estados modernos ${ }^{31}$.

Es en este momento de sus reflexiones cuando acuñará un nuevo concepto, el de Administración prestadora (Leistungsverwaltung o leistende Verwaltung), que opondrá al tradicional de Eingriffsverwaltung, característico del Estado liberal del siglo XIx. Eingriffsverwaltung y Leistungsverwaltung conformarán así, en su opinión, dos ámbitos distintos de actuación de la Administración: la Administración interventora, basada en la idea de libertad, y la Administración prestadora, basada en la participación del individuo en las prestaciones estatales. Se corresponderán, a su vez, con dos partes estructuralmente distintas, pero no incompatibles, del nuevo Derecho administrativo del siglo $\mathrm{xx}^{32}$. Esta construcción dual propuesta por Forsthoff hizo fortuna de inmediato, siendo acogida con gran éxito entre la doctrina iuspublicista

29 Léon DUGUIT, Las transformaciones del Derecho Público, op. cit., p. 84.

30 Para FORSTHOFF, las estructuras del Estado y del Derecho administrativo respondían a una sociedad propia de mediados del siglo xIx, pero que no se ajustaba ya a la realidad social y estatal de 1938. En este sentido, uno de los problemas radicaba en el hecho de que dentro de la dogmática liberal alemana solo tuviera cabida un concepto de policía negativo (cura advertendi mala futura), en el sentido de incluir la prevención de riesgos, pero no el denominado fomento positivo del bienestar (cura promovendi salutis). Ello limitó el proceso de sistematización del Derecho administrativo, que ante las transformaciones políticas y económicas de la moderna sociedad de masas a partir de la segunda mitad del siglo XIX careció de capacidad de reacción para hacerles frente. Cfr. Ernst FORSTHOFF, "Die Daseinsvorsorge als Aufgabe der modernen Verwaltung", op. cit., p. 24.

31 Ernst FORSTHOFF, "Die Daseinsvorsorge als Aufgabe der modernen Verwaltung”, op. cit., p. 23.

32 Ernst FORSTHOFF, "Anrecht und Aufgabe einer Verwaltungslehre", en Ernst FORSTHOFF, Rechtsfragen der leistenden Verwaltung, W. Kohlhammer Verlag, Stuttgart, 1959, pp. 47-63 (p. 52-54). 
germánica. Desde entonces, lo cierto es que está presente en la inmensa mayoría de los manuales alemanes de Derecho administrativo ${ }^{33}$.

Nótese cómo Forsthoff ha partido de la observación sociológica de la realidad para tratar de acomodar en la dogmática del Derecho administrativo las nuevas funciones estatales que surgen a partir de la "ciudad moderna". Su análisis es, en última instancia, una apelación a esa realidad y al uso de otras disciplinas no jurídicas (básicamente, la Sociología y la Ciencia de la Administración, pero también la Filosofía) como mecanismos para tratar de dar forma jurídica a las transformaciones sociales del momento y acomodar, en definitiva, el Derecho administrativo a la realidad de su tiempo. Una amplitud de onda en su análisis y pensamiento que, como señala Esteve Pardo, es un signo característico de muchos de los iuspublicistas europeos de la época: desde Jellinek, Schmitt, Leibholz o Smend (además del propio Forsthoff), a Giner de los Ríos, Gumersindo de Azcárate o Posada en España, Gaetano Mosca en Italia o Hauriou y Duguit, en Francia, entre otros ${ }^{34}$.

De este modo, y una vez sentadas las bases sociológicas de la procura existencial, Forsthoff tratará de atribuir a dicho concepto, en tanto que concepto originariamente no jurídico, sino extraído de la realidad sociológica, una concreta significación jurídica ${ }^{35}$. A discutir precisamente hasta qué punto logró su objetivo dedicaremos el último de los epígrafes del presente trabajo.

En todo caso, la lucidez de la reflexión sociológica forsthoffiana no debe llevarnos a pasar por alto algunos importantes puntos oscuros. Es cierto que, al menos en su construcción teórica, Forsthoff no pretendía la sustitución del Derecho administrativo liberal por el Derecho propio de la procura existencial, sino la convivencia y complementariedad entre ambos. Sin embargo, también es cierto que en dicha construcción la procura existencial ocupa una posición central y preeminente, en el sentido de que el resto de funciones estatales solo podrían desarrollarse adecuadamente si la existencia del individuo quedaba jurídicamente garantizada, primero, mediante su participación en las prestaciones de procura existencial ${ }^{36}$.

En su opinión, por lo tanto, las garantías típicamente liberales no bastaban ya para proporcionar al individuo la protección y la seguridad que exige al poder pú-

33 Puede consultarse, por ser seguramente el de mayor difusión durante las últimas décadas, el de Hartmut MAURER, Allgemeines Verwaltungsrecht (17.a ed.), Verlag C. H. Beck, Múnich, 2009, pp. 15 y 16. Existe traducción española de dicho manual, cfr. Hartmut MAURER, Derecho Administrativo. Parte General (traducción coordinada por Gabriel DOMÉNECH PASCUAL), Marcial Pons, MadridBarcelona-Buenos Aires, 2011.

34 José ESTEVE PARDO, El pensamiento antiparlamentario y la formación del Derecho público en Europa, op. cit., pp. 72-76, señalando también que, con el objetivo de desarrollar su crítica del sistema liberal y burgués, esta generación de iuspublicistas se sirvió de la Sociología, la Filosofía, la Psicología, la Literatura y hasta la Teología, y de sus instrumentos analíticos y conceptuales, para "obtener las claves para la comprensión del nuevo mundo" en el que se estaban adentrando y captar "con toda su hondura el nuevo signo de los tiempos para el Derecho público".

35 Ernst FORSTHOFF, “Anrecht und Aufgabe einer Verwaltungslehre”, op. cit., pp. 55- 57.

36 Ernst FORSTHOFF, "Folgerungen”, op. cit., p. 42. 
blico. Estas garantías individuales son necesarias, pero no suficientes; son necesarias, pero no primordiales, pues son irrealizables sin la previa participación en las prestaciones de Daseinsvorsorge. Con estos razonamientos Forsthoff se desliza peligrosamente hacia una de sus afirmaciones más polémicas: "los derechos fundamentales pertenecen a la historia" ${ }^{37}$, con la que rechazará un entendimiento puramente liberal de estos al considerar que, a la luz de la nueva realidad social, ya no sirven para proteger efectivamente al individuo ${ }^{38}$. Es más, de conformidad con esta concepción, Forsthoff parece estar sugiriendo que es el propio individuo el que prefiere renunciar a las libertades individuales de que disfruta en sociedad (Freiheit in der Gesellschaft), sacrificándolas a cambio de su participación en las prestaciones de la comunidad (Teilhabe an einer Gemeinschaft), lo que le libera de afrontar y responsabilizarse de su propia existencia ${ }^{39}$.

Se trata, en todo caso, de una corriente de pensamiento relativamente común durante el periodo de entreguerras, vinculada a la irrupción y avance de las masas en las instituciones políticas típicamente liberales y a su efecto disolvente de la identidad del individuo. Una tendencia que, en el ámbito del Derecho público, llevará al cuestionamiento del individuo y de los derechos individuales. A estas tesis se abonarán no solo aquellos iuspublicistas de marcada tendencia autoritaria -como sería el caso de Forsthoff durante los años treinta, y de otras figuras destacadas como Theodor Maunz-, sino también quienes habían adoptado una clara orientación social, como por ejemplo de Léon Duguit ${ }^{40}$. En cualquier caso, lo cierto es que aquella afirmación forsthoffiana, atendiendo al contexto del momento, se interpretó y entendió después como un acercamiento a posiciones nacionalsocialistas, cuando no como una clara identificación con ellas. Así, cuando en 1959 autorizó la reedición de Die Verwaltung als Leistungsträger, Forsthoff eliminaría aquella afirmación, en un claro intento por depurarlo de ambigüedades nacionalsocialistas ${ }^{41}$.

37 Ernst FORSTHOFF, "Die Daseinsvorsorge als Aufgabe der modernen Verwaltung”, op. cit., p. 22.

38 Ernst Forsthoff, "Folgerungen", op. cit., p. 39.

39 En este sentido Jens KERSTEN, "Die Entwiklung des Konzepts der Daseinsvorsorge im Werk von Enst Forsthoff”, op. cit., pp. 553 y 554. El propio Forsthoff era consciente de ello, preguntándose incluso cuáles eran los motivos que habían llevado al individuo del siglo xx a renunciar de forma plenamente consciente a las libertades individuales que tan altamente había valorado en el pasado para someterse a ligámenes que entonces no hubiera soportado. Cfr. Ernst FORSTHOFF, "Folgerungen", op. cit., p. 39.

${ }^{40}$ En este sentido señala Esteve Pardo que "se trata, desde luego, de posiciones que hoy nos pueden parecer aberrantes, pero que en aquellos años estaban bien extendidas en la Europa continental". Cfr. José ESTEVE PARDO, El pensamiento antiparlamentario y la formación del Derecho público en Europa, op. cit., pp. 94 y 52-54, así como también pp. 84-87, en las que destaca cómo el ataque a los derechos individuales e incluso su negación encontraron un apoyo fundamental en los análisis sociológicos del momento y en las aportaciones de Comte y Durkheim, influyendo decisivamente, por ejemplo, en autores como Léon Duguit.

${ }^{41}$ Así, en el Prólogo a la nueva edición de aquel trabajo llamaba la atención sobre el hecho de que había sido escrito y formulado atendiendo a una situación concreta (la de 1938), lo que exigía contextualizar convenientemente algunas de las afirmaciones entonces realizadas, en clara alusión a la 


\section{LOS CONCEPTOS JURÍDICOS DE PROCURA EXISTENCIAL (DASEINSVORSORGE), ADMINISTRACIÓN PRESTACIONAL (LEISTUNGSVERWALTUNG) Y RESPONSABILIDAD ADMINISTRATIVA SOBRE LA PROCURA EXISTENCIAL (DASEINSVERANTWORTUNG)}

\subsection{La construcción jurídica de la Daseinsverantwortung}

Según acabamos de señalar, Forsthoff sentará las bases sociológicas para la posterior teorización jurídica de un nuevo ámbito de funciones estatales surgidas al calor de la Revolución industrial y los cambios políticos y sociales que esta conllevó. En este sentido, Forsthoff situará, junto a la clásica "Administración de intervención" (Eingriffsverwaltung), la "Administración prestadora" (Leistungsverwaltung), que asumirá esas nuevas funciones estatales derivadas del industrialismo y la urbanización y vinculadas a los modos de vida de la "ciudad moderna". Tales funciones estatales consistirán, básicamente, en garantizar las necesidades de apropiación del individuo que son imprescindibles para una existencia digna y adecuada en el nuevo contexto de una sociedad industrial. Y estas nuevas funciones pasarán a ser consideradas responsabilidad de la Administración pública en su vertiente o faceta de Administración prestadora. Añadamos ahora que esta responsabilidad será, además, según Forsthoff, una responsabilidad jurídica: sobre la Administración prestadora recaerá la denominada responsabilidad existencial (Daseinsverantwortung), esto es, la responsabilidad de garantizar jurídicamente la satisfacción de las necesidades de apropiación, para lo cual dispondrá de un importante conjunto de medidas o dispositivos (y de potestades) que se aglutinarán también bajo la denominación de procura existencial o Daseinsvorsorge ${ }^{42}$.

Es interesante señalar que esta asunción de la Daseinsverantwortung por parte de la Administración es consecuencia directa de aquellas transformaciones sociales y económicas de la segunda mitad del siglo xIx, ya analizadas. En efecto, en el contexto de la sociedad preindustrial característica del Estado liberal -nos recuerda Forsthoffdicha responsabilidad era primordialmente individual. Los procesos de industrialización y urbanización, el derrumbamiento de la sociedad liberal burguesa y la consecuente aparición de conflictos sociales cambiarán esta situación, y convertirán dicha responsabilidad primero en colectiva (a través de la solidaridad del grupo) y luego

afirmación "los derechos fundamentales pertenecen a la historia". Léase al respecto el breve prólogo del autor, Ernst FORSTHOFF, "Vorwort", op. cit., passim. Por su parte, KERSTEN señala que a partir de sus escritos de 1941 (concretamente, de su conferencia Grenzen des Rechts, pronunciada en Königsberg el 12 de febrero de 1941) Forsthoff matizará el carácter totalizador de la Daseinsvorsorge, afirmando que, en cualquier caso y necesariamente, aquella debe ser adecuada y proporcionada a la personalidad del individuo, no pudiendo nunca someter su dignidad. Cfr. Jens KERSTEN, "Die Entwiklung des Konzepts der Daseinsvorsorge im Werk von Enst Forsthoff”, op. cit., pp. 555 y 556.

${ }_{42}$ Ernst FORSTHOFF, “Die Daseinsvorsorge als Aufgabe der modernen Verwaltung”, op. cit., p. 26. 
en pública, mediante la total asunción de la responsabilidad por parte del Estado ${ }^{43}$. Así, dado que en la sociedad industrial las personas han devenido dependientes de circunstancias ajenas a su voluntad, la responsabilidad existencial no puede recaer sobre ellas, pues no se hallan en situación de poder asumirla. En consecuencia, es al Estado, concretamente a su Administración, a quien corresponde la asunción de la responsabilidad sobre la existencia de sus ciudadanos ${ }^{44}$.

De este modo, la observación sociológica da paso a la elaboración jurídica. Forsthoff construye, utilizando los conceptos de Daseinsvorsorge, Daseinsverantwortung y Leistungsverwaltung, una Administración pública a quien corresponden "los deberes estatales de provisión de los bienes y prestaciones necesarias para una existencia humana razonable y adecuada" ${ }^{45}$. La idea de procura existencial, pues, define una nueva forma de relación entre el individuo y el Estado, basada no en la noción de libertad propia del Estado liberal sino en el concepto de participación del individuo en las prestaciones estales ${ }^{46}$. A dicha participación $-y$ especialmente a su aseguramiento jurídico- se le otorga la protección del Derecho público ${ }^{47}$. En este sentido -y como señalara entre nosotros Martín-Retortillo- es en dicha teorización donde radica, precisamente, el mérito de Forsthoff: haber sido capaz de "traducir aquellas observaciones de carácter sociológico a un terreno netamente jurídico y el haber procurado un lugar dentro de la dogmática jurídica a una Administración que se reconoce responsable del fin de la procura existencial” ${ }^{48}$. Cuestión distinta es si Forsthoff fue capaz, también, de dotar de contornos jurídicos suficientemente precisos al propio concepto de Daseinsvorsorge, como veremos seguidamente.

Uno de los efectos más importantes que se derivan de la asunción por parte del poder público de aquella responsabilidad existencial es el innegable incremento del poder estatal. Por un lado, la responsabilidad existencial del Estado hace imposi-

${ }^{43}$ Cfr. Ernst FORSTHOFF, "Die Daseinsvorsorge als Aufgabe der modernen Verwaltung", op. cit., pp. 26 y 27.

${ }_{44}$ Para Forsthoff se trata, en realidad, de un cambio en la distribución de riesgos regulada por el ordenamiento jurídico. Así, el ordenamiento jurídico del Estado liberal de Derecho, basado en la autonomía privada y en la libertad individual, permitía una posibilidad real de elección y de decisión entre diversos modos de comportamiento. A una responsabilidad individual del individuo le correspondía, lógicamente, una asunción individual de riesgos. En cambio, el Estado social se caracterizará por la dependencia del individuo, como consecuencia de la inexistencia de posibilidades reales de elección y decisión. Ello genera que el sistema de distribución de riesgos del Estado liberal pierda su sentido y su justificación jurídico-política; la necesidad de una procura existencial supraindividual y, consecuentemente, el riesgo se presenta ahora vinculado a la existencia colectiva de una comunidad estructurada, esto es, al Estado mediante su intervención. Cfr. Ernst FORSTHOFF, "Folgerungen”, op. cit., pp. 36 y 42.

45 En ello radica, según Maurer, el mérito de Forsthoff: en haber sido el primero en dotar de sentido jurídico la idea de una Administración prestadora. Cfr. Hartmut MAURER, Allgemeines Verwaltungsrecht, op. cit., p. 7.

46 Ernst FORSTHOFF, "Einleitung”, en Ernst FORSTHOFF, Rechtsfragen der leistenden Verwaltung, W. Kohlhammer Verlag, Stuttgart, 1959[1938], pp. 9-21, (p. 9).

47 Ernst FORSTHOFF, "Einleitung", op. cit., p. 10.

48 Lorenzo MARTÍN-RETORTILLO, "La configuración jurídica de la Administración pública y el concepto de Daseinsvorsorge", Revista de Administración Pública núm. 38, 1962, pp. 35-65 (p. 60). 
ble prescindir de él, pues él es quien suministra (o, como mínimo, garantiza) las prestaciones esenciales. Por otro, se incrementa también la injerencia estatal en el sistema económico: prácticamente nada es ajeno al Estado y las fronteras entre lo público y lo privado pierden sus contornos y se difuminan ${ }^{49}$. Además, la garantía de la procura existencial requiere necesariamente de un importante engranaje organizativo, de un aparato burocrático que actúe conforme a reglas racionales: dicha estructura organizativa es la Administración pública, que ve notablemente extendidas sus funciones y su importancia respecto del legislador. Es precisamente en este contexto en el que debe situarse su afirmación "los problemas constitucionales de nuestro tiempo son problemas administrativos" 50 .

De hecho, Forsthoff entiende que el peso preponderante que la dogmática iuspublicista tradicionalmente colocaba en el poder legislativo (y en la Constitución como corolario) debía trasladarse al ejecutivo por vía de una Administración fuerte, cuya actuación precisa y técnico-racional estuviera basada en la regularidad de su ejecución, en la distribución de asuntos, en un poder claro y contundente para dar órdenes y en unos funcionarios altamente cualificados ${ }^{51}$. La Administración prestadora forsthoffiana es, por lo tanto, una Administración altamente burocratizada y vinculada a la ley; una Administración, en definitiva, sometida al Derecho y en la que los funcionarios, en tanto que titulares de funciones estatales, actúan ejecutando instrucciones de conformidad con el marco legal correspondiente y asegurando de este modo la previsibilidad legal que se exigía y esperaba del Estado ${ }^{52}$. Es precisamente esta concepción la que permitiría explicar, quizás, el escaso éxito que la construcción forsthoffiana de la Daseinsvorsorge tuvo entre 1938 y 1945, especialmente entre el sector más ortodoxo del nacionalsocialismo, que solo admitía el sometimiento del Estado al Führer ${ }^{53}$.

49 El hecho de que el Estado garantice la procura existencial de sus ciudadanos le confiere también cierta estabilidad, pues es imposible su eliminación como organización, por cuanto ello supondría una afectación grave de los fundamentos de la vida de la población. Cfr. Enrst FORSTHOFF, "Die Daseinsvorsorge als Aufgabe der modernen Verwaltung Verwaltung", op. cit., pp. 28 y 29.

50 Ernst FORSTHOFF, "Sentido actual de las relaciones entre Estado y sociedad en Alemania", en Ernst FORSTHOFF, Problemas actuales del Estado social de Derecho en Alemania, Publicaciones del Centro de Formación y perfeccionamiento de Funcionarios, Madrid, 1966, pp. 13-35 (pp. 25-33).

51 Sin embargo, Forsthoff alcanza también a vislumbrar los riesgos que esta traslación del peso político puede conllevar, mostrando especial preocupación por la posibilidad de que la creciente preponderancia de la Administración frente al Parlamento pueda llegar a disolver el principio democrático, en tanto no es el órgano que encarna la voluntad popular el que verdaderamente toma las decisiones. Cfr. Ernst FORSTHOFF, "Anrecht und Aufgabe einer Verwaltungslehre", op. cit., p. 49 y Ernst FORSTHOFF, "Sentido actual de las relaciones entre Estado y sociedad en Alemania", op. cit., pp. $25-33$.

52 Es curioso observar, en todo caso, cómo Forsthoff caracteriza la Administración prestadora como una Administración típicamente burocrática y jerárquica; característica, en este sentido, del Estado liberal que tanto criticó. Cfr. las interesantes reflexiones de Dieter SCHEIDEMANN, Der Begriff Daseinsvorsorge: Ursprung, Funktion und Wandlungen der Konzeption E.Forsthoff, Muster-Schmidt, Göttingen, 1991, pp. 48-53.

${ }_{53}$ Cfr. Michael RONELLENTITSCH, "Daseinsvorsorge als Rechtsbegriff. Aktuelle Entwicklungen im nationalen und europäischen Recht", en Willi BLÜMEL (ed.) Ernst Forsthoff: Kolloquium aus 


\subsection{El intento de perfilar jurídicamente los contornos de la Daseinsvorsorge}

Según lo dicho, por lo tanto, Forsthoff será el primer autor, en el ámbito de la doctrina iuspublicista alemana, en atribuir a la Administración pública los deberes jurídicos de provisión de los bienes y servicios necesarios para una vida digna y adecuada del individuo. Mediante la Daseinsverantwortung (la responsabilidad de garantizar las necesidades de apropiación o de procura existencial) imputa una obligación jurídica a la Administración pública a la que define, cuando ejerce las funciones propias de dicha responsabilidad, como Administración prestadora. Este primer paso de atribución de la responsabilidad jurídica de la procura a la Administración es, pues, evidente. El problema aparece en el momento inmediatamente posterior. Específicamente, en el momento de definir de forma precisa y concreta qué es la procura existencial, esto es, cuáles son las necesidades de apropiación: ¡cómo se concretan, definen y caracterizan jurídicamente? Forsthoff tratará de ofrecer una respuesta a tales preguntas, pero es precisamente en el momento de delimitar jurídicamente qué debe entenderse por procura existencial, así como en concretar el alcance de su exigibilidad jurídica, cuando su construcción encuentra mayores debilidades.

En efecto, cuando en 1938 se aproxime de forma positiva al concepto de Daseinsvorsorge, Forsthoff realizará una delimitación amplísima: incluirá entre las necesidades de apropiación la garantía de una adecuada relación salario-precio, el derecho al trabajo y a una remuneración equitativa, la regulación de la demanda, producción y consumo o la aportación de aquellas prestaciones de las que depende el hombre en las sociedades modernas (tales como el suministro de agua, gas o electricidad, pero también medios de comunicación, correo, teléfono, seguridad sanitaria o invalidez $)^{54}$. Es evidente que en este amplio listado se incluye no solo la realización (o garantía) por parte de la Administración de actividades netamente prestacionales sino también la adopción, por parte de los poderes públicos (incluido el legislador) de medidas gené-

Anlass des 100. Geburtstags von Porf. Dr. H.c. Ernst Forsthoff, Wissenschaftliche Abhandlungen und Reden zur Philosophie, Politik und Gesitesgeschichte, Band 30, Ducker \& Humblot, Berlín, 2003, pp. 53-114 (pp. 56 y 60-63), y también Horst DREIER, "Die deutsche Staatsrechtslehre in der Zeit des Nationalsozialismus", op. cit., p. 17 nota a pie de página 39. En este mismo sentido, incluso su controvertida concepción del "Estado Total" implicaría un sometimiento del mismo a cauces jurídicos, no pudiendo verse reducido al mando o dirección del "líder" (Führer) -a diferencia de lo sostenido por el movimiento nacionalsocialista, para quien el Estado podía basarse en la persona del líder. Cfr. Hans Hugo KLEIN, "Der totale Staat. Betrachtungen zu Ernst Forsthoffs gleichnamiger Schrift von 1933", op. cit., pp. 22 y 32-36 y Wolfgang PAULY, "Die deutsche Staatsrechtslehre in der Zeit des Nationalsozialismus", op. cit., pp. 80 y 81. En el mismo sentido, señala Stolleis que el escrito Der totale Staat era, sin duda, un escrito antiburgués, antiformal y negador del concepto de libertad, pero alejado de la pura arbitrariedad. Cfr. Michael STOLLEIS, Geschichte des Öffentlichen Rechts in Deutschand, Dritter Band 1914-1945, C. H. Beck, Múnich, 1999, p. 202 y también Jens KERSTEN, "Die Entwiklung des Konzepts der Daseinsvorsorge im Werk von Enst Forsthoff", op. cit. pp. 548-550, quien apunta las fuertes críticas que Forsthoff recibiría de Rosenberg y Freisler.

54 Ernst FORSTHOFF, "Die Daseinsvorsorge als Aufgabe der modernen Verwaltung", op. cit., p. 28 y Ernst FORSTHOFF, "Folgerungen”, op. cit., pp. 38 y 39. 
ricas tendentes a la intervención y a la regulación pública de la actividad económica (por ejemplo, mediante la regulación de las relaciones de trabajo en el ámbito del Derecho laboral o en los mercados). Forsthoff está, por lo tanto, utilizando un concepto amplio de procura existencial; tan amplio que, de hecho, termina por identificarse prácticamente con los fines del Estado (social): la satisfacción de las necesidades del individuo con tal de asegurarle una existencia materialmente digna y adecuada ${ }^{55}$. Posiblemente, el hecho de haber construido un concepto sociológico -y no jurídico- de Daseinsvorsorge es lo que le impide perfilar adecuadamente sus contornos jurídicos ${ }^{56}$.

En relación con esta concepción amplia de la Daseinsvorsorge, conviene llamar la atención sobre dos cuestiones. En primer lugar, nótese cómo únicamente el último de los elementos más arriba mencionados podría incluirse claramente dentro de lo que cabría considerar, jurídicamente hablando, como servicios públicos (o Daseinsvorsorge en sentido estricto, que es la categoría que se ha mantenido hasta la actualidad). En cambio, la garantía de una adecuada relación salario-precio, una remuneración equitativa o una regulación (pública, se entiende) de la demanda, la producción o el consumo son, como ya se ha indicado, fines del Estado que pueden conseguirse a través de muy distintas técnicas o instrumentos (no solo ni primordialmente jurídico-administrativos).

En segundo lugar, y especialmente respecto de los servicios públicos -que sería la actividad prestacional en sentido estricto-, el propio Forsthoff señala lo problemático que resulta su delimitación material, pues esta exige necesariamente tener que precisar la extensión del ámbito de dependencia del individuo y el nivel mínimo que se puede considerar como razonable ${ }^{57}$. En efecto, la cuestión clave $-y$ problemáticaradica en el entendimiento de lo que sea necesario para la existencia del individuo, ya que tales necesidades no son constantes, sino que dependen de las circunstancias de

55 Junto a esta delimitación positiva, Forsthoff intenta también perfilar el concepto mediante una delimitación negativa y, así, excluirá del mismo aquellas prestaciones a cargo de la Administración en las que falte el elemento de generalidad, así como las tareas de carácter soberano en el sentido tradicional (policía, seguridad y orden público), la función jurisdiccional y las relaciones jurídicas bilaterales (derivadas, por ejemplo, de la pertenencia a corporaciones profesionales). Cfr. Ernst FORSTHOFF, "Folgerungen", op. cit., pp. 37 y 38. Esta misma posición la mantendrá también en sus escritos sobre procura existencial de finales de los años cincuenta, por ejemplo, en Ernst FORSTHOFF, "Einleitung", op. cit., pp. 12 y 13. Por el contrario, su posición respecto de la inclusión de la regulación de un salario adecuado como parte de las tareas propias de la procura existencial sí variará con el tiempo. Así, en 1938 lo había considerado parte integrante de dicho conjunto de prestaciones, mientras que lo excluirá expresamente en sus escritos de 1958. Forsthoff justificará tal exclusión sobre la base de que el mismo Estado habría renunciado a la decisión estatal al respecto en favor de los convenios colectivos sobre salarios, concluyendo que, con ello, la procura del salario adecuado ha pasado a ser una función de la sociedad; en concreto, una decisión de las organizaciones de patronos y los sindicatos de obreros. Ernst FORSTHOFF, "Einleitung", op. cit., p. 19. Tal afirmación debe ponerse en relación con su particular visión del modelo de Estado social alemán, próxima al neocorporativismo. Cfr. Nuria MAGALDI, Procura existencial, Estado de Derecho y Estado Social, op. cit., p. 93.

56 De esta opinión es Jens KERSTEN, "Die Entwiklung des Konzepts der Daseinsvorsorge im Werk von Enst Forsthoff”, op. cit., p. 554.

57 Ernst FORSTHOFF, "Einleitung", op. cit., pp. 10 y 11. 
cada momento histórico, cultural y social ${ }^{58}$. Por ello, y como señaló entre nosotros Lorenzo Martín-Retortillo, no es posible reducir la Daseinsvorsorge -en su dimensión prestacional- a una fórmula concreta y cerrada, como si fuera un concepto meramente formal ${ }^{59}$ : las prestaciones que deben satisfacerse se caracterizan por su relatividad tanto en el tiempo como en el espacio. Una afirmación que a día de hoy sigue siendo plenamente válida.

Además de tratar de delimitar el concepto de procura existencial, concretando cuáles serían las necesidades de apropiación (las prestaciones) que este incluiría, Forsthoff intentará también perfilar jurídicamente cuáles son los elementos que lo caracterizarían. Como ya señalé en un trabajo anterior ${ }^{60}$, cabe destacar cuatro principales características que Forsthoff predicó de la procura existencial, sin que se aprecien diferencias sustantivas esenciales entre sus escritos de 1938 y los posteriores de 1958.

En primer lugar, y como ya hemos indicado anteriormente, para Forsthoff la procura existencial supone una nueva forma de relación entre el individuo y el Estado que no se basa ya en la noción de libertad propia del Estado liberal sino en el concepto de participación del individuo en las prestaciones del Estado ${ }^{61}$. A dicha participación -y especialmente a su aseguramiento jurídico- se le otorga la protección del Derecho público. Ahora bien -y este sería el segundo aspecto- esta garantía jurídico-pública no prejuzga, en ningún caso, las formas jurídicas a través de las cuales la Administración ejercerá efectivamente tales funciones, siendo posible, por lo tanto, la utilización de formas y procedimientos jurídico-privados. De hecho, precisamente que su ejercicio sea posible a través de formas jurídico-privadas justifica el que deban gozar de la protección del Derecho público ${ }^{62}$.

En tercer lugar, Forsthoff es contundente en negar que de esa responsabilidad jurídico-pública puedan extraerse consecuencias jurídicas directas ni deducirse pre-

58 Ernst FORSTHOFF "Einleitung", op. cit., p. 12. Así, Forsthoff se pregunta, por ejemplo, si el elemento clave podría ser la distinción entre abastecimientos necesarios y no necesarios, aunque en cualquier caso parece entender que el concepto de procura existencial no puede limitarse al mínimo de existencia vital. En este sentido, afirma que sería contrario a la esencia del moderno Estado social y distribuidor limitar las funciones del concepto de procura existencial al "estándar mínimo que se desprende de la esfera vital del individuo”, esto es, al mínimo existencial. Traza, de este modo, una línea diferenciadora entre la procura existencial y la asistencia social, a la que ya nos referimos en páginas anteriores. Por otro lado, conviene destacar también cómo Duguit se planteaba igualmente cuáles eran las actividades cuyo cumplimiento debía considerarse obligatorio para los gobernantes y que constituían el objeto de los servicios públicos. Y coincidía en su respuesta parcialmente con Forsthoff, al entender que "es imposible dar a la cuestión una respuesta general", puesto que en ella hay "algo esencialmente variable, evolutivo”. Cfr. Léon DUGUIT, Las transformaciones del Derecho público, op. cit., pp. 100 y 101.

59 Lorenzo MARTÍN-RETORTILLO, "La configuración jurídica de la Administración Pública y el concepto de Daseinsvorsorge", op. cit., pp. 48 y 49.

60 Nuria MAGALDI, Procura existencial, Estado de Derecho y Estado Social, op. cit., pp. 90-92. Con anterioridad ya Martín-Retortillo había tratado también de caracterizar y ordenar jurídicamente la Daseinsvorsorge forsthoffiana en Lorenzo MARTÍN-RETORTILLO, "La configuración jurídica de la Administración Pública y el concepto de Daseinsvorsorge”, op. cit., pp. 48-54.

${ }_{61}$ Ernst FORSTHOFF, "Einleitung", op. cit., p. 9.

${ }^{62}$ Ibid., p. 10. 
tensiones ante los tribunales mediante su invocación ${ }^{63}$. Niega, en este sentido, la posibilidad de que nos encontremos, cuando hablamos de prestaciones de procura existencial, ante derechos subjetivos directamente ejercitables ante los tribunales ni frente a derechos fundamentales constitucionalmente reconocidos. Y, por último, Forsthoff afirmará también rotundamente que la Administración prestadora, cuando realiza funciones de procura existencial, puede sustraerse -y de hecho se sustrae- a la normativa en materia de defensa de la competencia, al entender que una empresa encargada de la provisión de tales prestaciones realiza funciones de procura existencial y no de mercado ${ }^{64}$. Además, para Forsthoff la Administración de la Daseinsvorsorge no ostenta el monopolio en la realización de tales funciones que, por lo tanto, podrán también ser desempeñadas por o con la colaboración de sujetos privados ${ }^{65}$.

Aunque no lo señale de forma expresa, parece evidente que cuando Forsthoff predicaba tales características jurídicas de la procura existencial estaba utilizando un concepto restringido o estricto de la misma, limitado a las actividades prestacionales realizadas o garantizadas por la Administración pública para la satisfacción de las necesidades de la colectividad. Solo en tales supuestos tiene sentido la discusión sobre su sometimiento o no a las normas de la competencia, o la consideración sobre la posibilidad de que la prestación no la realice directamente la Administración sino un privado controlado por esta. Es significativo, en este sentido, el ejemplo que utiliza el propio Forsthoff en sus trabajos: una empresa dedicada al suministro energético y sometida, por lo tanto, a la entonces vigente Ley en materia de energía, de 1935 -y, por ello, sometida a vigilancia estatal y a determinadas obligaciones jurídicopúblicas- nunca tendría la consideración de "empresa dominante" en el sentido de dicha ley y del Derecho de la competencia, aunque de facto tuviera una posición de dominio en el mercado. Y ello porque dicha empresa estaría realizando tareas de procura existencial $^{66}$.

Cuestión distinta es, en cambio, el concepto de Daseinsvorsorge utilizado por Forsthoff para rechazar la consideración de las prestaciones de procura existencial

63 Ibid., p. 13.

64 Ibid., p. 11.

65 Ernst FORSTHOFF, "Folgerungen”, op. cit., pp. 45 y 46. En este sentido, Forsthoff postulaba la necesidad de elaborar una normativa estatal con rango de Ley que regulara los principios generales que debían regir las relaciones de prestación cuando entraran en juego sujetos privados -como prestadores-. En particular, consideraba esencial el establecimiento de límites a la autonomía de dichos sujetos prestadores. Además, dicha Ley tendría que regular también un deber general de suministro para todas aquellas prestaciones consideradas esenciales para la existencia vital, así como lo mecanismos jurídicos de defensa que el ciudadano tendría a su disposición (qué vía jurisdiccional, básicamente) frente a quien, debiendo realizar la prestación, la denegaba o no la prestaba.

En relación con esta cuestión, Lorenzo MARTÍN-RETORTILLO, "La configuración jurídica de la Administración Pública y el concepto de Daseinsvorsorge”, op. cit., pp. 55 y 56, apuntaba, con acierto, que la regulación de las relaciones con los prestadores privados adquirió mayor importancia y relieve con la aprobación de la Ley Fundamental de Bonn, que "reconoce de modo directo la cooperación de los particulares con el Estado para la realización del interés general y en el que se admite ampliamente el principio de subsidiariedad con todas sus consecuencias".

66 Ernst FORSTHOFF, "Einleitung”, op. cit., p. 11. 
como directamente invocables ante los tribunales o la negación de su consideración como derechos fundamentales. En este sentido, conviene recordar cómo, durante mucho tiempo, la creación y el establecimiento de servicios públicos en España no tuvo la consideración de una actividad administrativa que pudiera ser directamente exigible ante los tribunales; de hecho, fue necesaria la incorporación del actual art. 18.1 letra g) de la Ley Reguladora de las Bases del Régimen Local para que, en nuestro ordenamiento jurídico, los vecinos tuvieran a su disposición un instrumento que les permitiera acudir a los tribunales para reclamar el establecimiento o la prestación de servicios públicos locales obligatorios. No deben, por lo tanto, sorprender afirmaciones como la entonces formulada por Forsthoff en relación con la imposibilidad de que prestaciones de Daseinsorsorge -en el sentido prestacional del término- puedan dar lugar a derechos directamente enjuiciables ante los tribunales ordinarios ${ }^{67}$.

Por otra parte, si tomamos el concepto amplio de Daseinsvorsorge, e identificamos las prestaciones de procura existencial con los fines del Estado social, tampoco es insólito sostener, incluso a día de hoy, que, al menos en parte, estos no sean directamente exigibles ante los tribunales, sino que requieran la adopción o el desarrollo de medidas legislativas o administrativas previas. Piénsese, por ejemplo, en los principios rectores de la política social y económica (arts. 39 a 52 de la Constitución española) o en los principios de la Carta de Derechos Fundamentales de la Unión Europea (art. 52.2). Ello es coherente, además, con la construcción de Forsthoff sobre la incompatibilidad (constitucional) entre Estado de Derecho y Estado social, según la cual este último se circunscribiría estrictamente al ámbito de la Administración (y de la legislación ordinaria), quedando por lo tanto excluido del ámbito de la Constitución (que sería el propio del Estado de Derecho) ${ }^{68}$.

Lo que sí parece innegable, en cualquier caso, es la dificultad de perfilar jurídicamente con total precisión un concepto amplio de Daseinsvorsorge. La asunción de un concepto amplio (que incluya todas las prestaciones estatales) impide dotarlo de contornos jurídicos claros y perfectamente delimitados. En tal caso, el concepto forsthoffiano de Daseinsvorsorge se aproxima más bien a la -hoy ya- clásica función del Estado social, llegando prácticamente a identificarse con él ${ }^{69}$. Así, únicamente cuando desgajamos del concepto amplio parte de las funciones propias de ese Estado social (que incluyen desde la regulación del salario hasta la intervención en la producción o la demanda en el mercado) y limitamos el concepto de Daseinsvorsorge a actividades estrictamente prestacionales (a los típicos servicios públicos) es posible

${ }^{67}$ En línea con esta idea, MARTÍN-RETORTILLO señalaba que el hecho de que las prestaciones de Daseinsvorsorge no fueran directamente justiciables no significaba nada en contra de su significación jurídica, ni tampoco excluía la posibilidad de utilizar otros mecanismos jurídicos para su defensa, desde las garantías del procedimiento administrativo hasta las vías de participación de los administrados o el control político. Cfr. Lorenzo MARTÍN-RETORTILLO, "La configuración jurídica de la Administración Pública y el concepto de Daseinsvorsorge", op. cit., pp. 51 y 52.

68 Cfr. Nuria MAGALDI, Procura existencial, Estado de Derecho y Estado Social, op. cit., pp. 119-145.

69 Rotundamente en este sentido Jens KERSTEN, "Die Entwiklung des Konzepts der Daseinsvorsorge im Werk von Enst Forsthoff', op. cit., p. 556. 
hablar de una categoría compleja, pero jurídicamente acabada. Y este paso es, quizás, el que Forsthoff no fue capaz de dar. De ahí las dudas que, a pesar de todo, han existido desde entonces en torno a la validez y utilidad, en términos jurídicos, de su Daseinsvorsorge ${ }^{70}$. Como apunta Maurer en su Allgemeines Verwaltungsrecht, "la noción de procura existencial se ha convertido con el tiempo en un bien común pero también, y debido tanto a su relevancia jurídica como a su ámbito y alcance material, en un concepto discutido" ${ }^{71}$.

\subsection{Daseinsvorsorge y principio de subsidiariedad}

Un aspecto que suele pasar desapercibido en la construcción forsthoffiana es cómo en esta late claramente el principio de subsidiariedad de la intervención pública. A pesar de haber sido el primero en teorizar las nuevas funciones del poder público y, particularmente, de la Administración prestadora, lo cierto es que, paradójicamente, Forsthoff siempre postuló que -cuándo y dónde sea posible- las funciones de procura existencial deben realizarse primariamente por y desde la sociedad. Esta posición se observa con mayor claridad en sus escritos sobre Daseinsvorsorge de finales de los ańos cincuenta, pero está ya presente en sus primeros trabajos de 1938. Es decir, y como hemos sostenido en otro lugar, no cabe hablar de un radical cambio de postura en Forsthoff en relación con la procura existencial entre sus trabajos de los años treinta y los de los años cincuenta. La aparente diferencia de planteamiento no es, en realidad, tal diferencia: simplemente, la situación política, social y económica entre ambos momentos era radicalmente distinta, lo que obligaba a una mayor extensión de la actuación de la Administración prestadora en 1938 y a que, por el contrario, la intervención administrativa en 1958 se replegara ${ }^{72}$.

En este sentido, y siempre sobre la base de las profundas transformaciones que supuso la Revolución industrial, la situación de Alemania en 1938 era una situación de auténtica crisis y emergencia: en opinión de Forsthoff, durante el periodo weimariano la sociedad fue incapaz de constituirse en orden propio y autónomo debido, en buena medida, a los efectos de la Primera Guerra Mundial. Como consecuencia

${ }^{70}$ Ilustrativo de tales dudas es, por ejemplo, el epígrafe final del trabajo Jens KERSTEN, "Die Entwiklung des Konzepts der Daseinsvorsorge im Werk von Enst Forsthoff", pp. 565 y ss., que lleva por título "Was bleibt von Ernst Forsthoff?" (“¿Qué queda de Ernst Forsthoff?”) y en el que reflexiona, precisamente, sobre las limitaciones jurídicas de la Daseinsvorsorge. Para él se trata no tanto de un concepto jurídico-dogmático perfilado sino de una explicación para justificar la legitimidad social y política del Estado (y de su poder y autoridad) en la nueva sociedad industrial (por contraposición a la anterior sociedad liberal burguesa).

${ }_{71}$ Hartmut MAURER, Allgemeines Verwaltungsrecht, op. cit., p. 7.

72 En el mismo sentido Lorenzo MARTÍN-RETORTILLO, "La configuración jurídica de la Administración pública y el concepto de Daseinsvorsorge", op. cit., pp. 54-56, para quien el hecho de que la Administración pública no monopolizara las tareas de procura existencial era una idea fundamental en la construcción de Forsthoff desde el primer momento y, muy especialmente, después de la aprobación de la Ley Fundamental de Bonn. 
del conflicto bélico y de la posterior crisis económica de 1929, se produjo lo que Forsthoff denomina una "mixtificación" entre Estado y sociedad: por un lado, el Estado se ve obligado a intervenir económicamente en el seno de la sociedad (políticas de construcción de viviendas, agrícola, monetaria, etc., además de, obviamente, la prestación de todos aquellos servicios vinculados a la "ciudad moderna"); por otro, la sociedad se politiza y genera, en su mismo seno, fuerzas políticas (partidos, pero también grupos de interés económico) que entrarán en conflicto y amenazarán al Estado, justificándose la intervención estatal en el curso del devenir social ${ }^{73}$. Por todo ello, durante el periodo weimariano se consideró que solo el Estado sería capaz de reordenar una economía y una sociedad que habían sido destruidas ${ }^{74}$.

Por el contrario, la Alemania de los años cincuenta es una Alemania marcada por el crecimiento económico y la estabilidad política, en la que se ha consolidado el Estado del bienestar. La seguridad material derivada de la generalización de ciertas prestaciones sociales y de la homogeneización de las condiciones de vida ha dado lugar a una desideologización política de estas sociedades industriales avanzadas ${ }^{75}$. En estas sociedades los ciudadanos no votan ya en función de su ideología sino de sus intereses. Así, un ciudadano no vota según su ideología liberal, socialista o conservadora, sino atendiendo a sus intereses como agricultor o importador, esto es, en función de los intereses que tenga en relación con las prestaciones que pueda ofrecerle el Estado, de modo que, de hecho, "la lucha por participar en la formación de esa voluntad (del Estado) es lucha por participar en la redistribución" ${ }^{76}$. En esta sociedad técnico-industrial de la década de los cincuenta la procura existencial pasa a ser, primariamente, función complementaria de la sociedad ${ }^{77}$. Forsthoff evoca, así, un retorno a la autonomía del individuo en la sociedad y una menor intervención estatal: la estabilidad política y económica se transmite al individuo, quien vuelve a concebir el mundo y su propia existencia como -hasta cierto punto- asegurada ${ }^{78}$. El

73 Cfr. Ernst FORSTHOFF, “Anrecht und Aufgabe einer Verwaltungslehre”, op. cit., p. 14 y Ernst FORSTHOFF, "Sentido actual de las relaciones entre Estado y sociedad en Alemania”, op. cit., p. 16.

74 Ernst FORSTHOFF, "Trasformazioni Trasformazioni strutturali della democrazia moderna" (1964), en Alessandro MANGIA, L'ultimo Forsthoff. Scritti 1961/1969 di E. Forsthoff su Costituzione ed amministrazione tradotti e commentati, op. cit., p. 148.

75 Ernst FORSTHOFF, "Einleitung”, op. cit., pp. 14-17. Ernst FORSTHOFF, "Sentido actual de las relaciones entre Estado y sociedad en Alemania", op. cit., pp. 19-21; Ernst FORSTHOFF, "Trasformazioni strutturali della democrazia moderna”, op. cit., pp. 148-150. Tal desideologización la percibe en relación al sistema de partidos políticos, aludiendo implícitamente a los catch-all-parties teorizados por Kirchheimer.

76 Ernst FORSTHOFF, “Problemas constitucionales...”, op. cit., pp. 55-57.

77 Forsthoff señala que la función complementaria más importante que ha de llevar a cabo el Estado es la igualdad social, al no estar su consecución al alcance de la sociedad industrial autónoma y autorregulada. Dentro de estas funciones del Estado FORSTHOFF se refiere, por un lado, a la asistencia a grupos de población marginados y no integrados y, por otro, a una serie de nuevas funciones que van surgiendo con el desarrollo de la moderna sociedad industrial (construcción de carreteras, educación y enseńanza). Cfr. Ernst FORSTHOFF, "Sentido actual de las relaciones entre Estado y sociedad en Alemania”, op. cit., pp. 27 y 28.

78 Ernst FORSTHOFF, "Sentido actual de las relaciones entre Estado y sociedad en Alemania”, op. cit., pp. 18-23. Forsthoff no está sosteniendo que el Estado moderno deba quedar totalmente al margen; 
vínculo con el principio de subsidiariedad parece, pues, evidente. Así, en situaciones normales, muchas de las funciones estatales de procura existencial pueden y deben ser devueltas a la sociedad, pero siempre con la seguridad de que, en caso de urgencia o crisis, emergerá de nuevo la procura existencial ${ }^{79}$.

Ello no supone, en ningún caso, afirmar que Forsthoff postulase la desaparición de la procura existencial en sus escritos de los años cincuenta. Todo lo contrario: Forsthoff era plenamente consciente de que parte de las prestaciones vinculadas a la Daseinsvorsorge habían surgido irremediablemente (por necesidad y no por voluntariedad) con la forma de vida urbana; se estaba refiriendo, lógicamente, a los servicios de la "ciudad moderna". En relación con tales prestaciones, por lo tanto, no habría vuelta atrás, salvo un improbable retroceso en la forma de vida urbana y en el desarrollo tecnológico-industrial. Todo ello sin perjuicio de las posibilidades de transformar la responsabilidad directa del Estado en la prestación en una responsabilidad de inspección o control sobre aquellos sujetos privados a quienes se podría transferir, en su caso, la provisión de la prestación ${ }^{80}$.

A la vista de cuanto se ha dicho, resulta claro que para Forsthoff la dependencia del individuo respecto de las prestaciones estatales era insatisfactoria, aunque inevitable. En este sentido, admitiendo que no era posible prescindir de las formas del Estado social, aspiraba a que los individuos pudieran recuperar y ostentar cuantos ámbitos de dominio fuera posible, lo que permitiría aumentar su independencia respecto del Estado ${ }^{81}$.

\section{CONCLUSIONES}

El presente trabajo se ha centrado en el análisis de la que constituye, sin género de dudas, la gran aportación de Ernst Forsthoff al Derecho público alemán de la posguerra y al modelo de Estado social de la República Federal de Bonn: el concepto de procura existencial (Daseinsvorsorge) y, estrechamente vinculado a este, el de Administración prestadora (Leistungsverwaltung). A lo largo de las páginas precedentes hemos constatado cómo Forsthoff construyó, primero, un concepto sociológico de procura existencial a partir de la observación de las transformaciones sociales, económicas y políticas de su época. Una época que -vale la pena recordar- abarca desde el final del Imperio alemán hasta la República federal de Bonn, pasando por la convulsa experiencia weimariana, el régimen totalitario del nacionalsocialismo y la segunda guerra mundial.

por el contrario, este sigue, por un lado, desempeñando las tareas estatales clásicas -política exterior, asuntos de interior, política cultural, defensa- y, por otro, colabora con esta economía moderna en alto grado autorregulada, esencialmente a través de las asociaciones y los grupos de interés económico.

79 Ernst FORSTHOFF, "Einleitung", op. cit., pp. 20 y 21.

${ }^{80}$ Ernst FORSTHOFF, "Folgerungen", op. cit., p. 45.

81 Ernst FORSTHOFF, "Folgerungen", op. cit., p. 44 y Ernst FORSTHOFF, "Problemas constitucionales del Estado Social”, en Ernst FORSTHOFF/Wolfgang ABENDROTH/ Kar DOEHRING, El Estado Social, Centro de Estudios Constitucionales, Madrid, 1986 [1963], pp. 43-69 (p. 66). 
Forsthoff fue un agudo observador de la realidad social, política y económica y de las transformaciones que esta estaba experimentando desde el último tercio del siglo xIx. Vislumbró con claridad los cambios sociológicos derivados de la Revolución industrial y de los fenómenos de urbanización e industrialización a ella asociados, percibiendo el traumático proceso de transición desde el Estado liberal burgués del siglo XIX a la sociedad de masas que se abría pasó con fuerza ya a principios del siglo Xx.

A partir de la observación de este contexto, Forsthoff construyó su concepto sociológico (y prejurídico) de procura existencial: la Revolución industrial y la urbanización de la sociedad dan lugar a la pérdida de independencia del individuo, que ya no puede proveerse a sí mismo de los bienes y abastecimientos que necesita, sino que debe hacerlo desde fuera, relacionándose con otros sujetos, mediante la apropiación. Y esta apropiación supone la participación en las prestaciones de la Administración pública. Obsérvese, además, cómo en esta teoría forsthoffiana de la Daseinsvorsorge Forsthoff crea y acuña conceptos sociológicos propios, tales como el espacio vital dominado (beherrschter Lebensraum), el espacio vital efectivo (effektiver Lebensraum) o la necesidad social (soziale Bedüruftigkeit).

Pero Forsthoff no se quedó en la observación y teorización sociológica, sino que fue capaz de dar un paso más, traduciendo los cambios observados en la organización social en un nuevo modelo de Estado y de Administración. Consciente de que no había vuelta atrás en relación con el cambio social operado (la urbanización y el advenimiento de la sociedad de masas), consideraba imprescindible que el Derecho público se dotara de nuevos instrumentos y conceptos, pues las fórmulas y los métodos jurídicos típicos del Estado liberal y de su Derecho se revelaban insuficientes. En este sentido, desde una aproximación propia de la Teoría del Estado, describió las nuevas formas de relación entre Estado y sociedad, lo que, a su vez, le llevó a definir una nueva posición institucional del Estado y de su Administración pública. De este modo, junto a la Eingriffsverwaltung -la Administración propia del Estado liberal, basada en la idea de libertad del individuo frente al Estado- colocó la noción de Leistungsverwaltung. A esta Administración prestadora Forsthoff le atribuyó la responsabilidad jurídica de garantizar la satisfacción de las necesidades de apropiación; en otras palabras, le impuso la obligación de proveer a los individuos con los bienes y prestaciones necesarios para que puedan llevar una existencia adecuada y digna.

Por último, tras la observación sociológica de la procura existencial y la configuración de las nuevas funciones del Estado y de su Administración, Forsthoff buscó dar un tercer y definitivo paso, dotando de contornos jurídicos al propio concepto de Daseinsvorsorge. En este sentido, cuenta en su haber con el hecho de haber sido el primer iuspublicista alemán en preguntarse, de forma sistemática y ordenada, por la configuración jurídica de ese nuevo Estado y de su Administración prestadora; más concretamente, por la configuración jurídica de las prestaciones que definen los nuevos fines del Estado y de las que su Administración se responsabiliza. Forsthoff planteó, sin duda, las preguntas jurídicas adecuadas: ¿cuál es la posición constitucional de los nuevos fines del nuevo Estado social? ,¡cuál es su exigibilidad jurídica?, ¿cuál es el ámbito material de las prestaciones de procura existencial?, ¿pueden determinarse 
con carácter absoluto cuáles son las prestaciones concretas que se incluyen dentro de la procura existencial?, ¿cuáles son las potestades de la Administración prestadora a la hora de proveer bienes y servicios de Daseinsvorsorge?, ¿ ¿rige en tales supuestos el Derecho de la competencia?, ¿deben prestarse de forma monopolística por el poder público o es posible la participación de sujetos privados? En caso de que estos últimos puedan participar en la provisión de bienes y servicios, ¿cuáles son las relaciones jurídicas que se establecen con los ciudadanos y respecto de la Administración?, ¿podría el ciudadano exigir la prestación a los privados que tienen encargada su prestación? En tal caso, ¿ante qué jurisdicción?

Sin embargo, en muchos casos no logró ofrecer soluciones jurídicas satisfactorias, y en otros ni siquiera logró articular una concreta respuesta jurídica; por ello, el tercer y último paso en su construcción científica -la caracterización jurídica de la Daseinsvorsorge- quedó incompleto, lo que, en opinion de parte de la doctrina, le resta parte de su utilidad práctica. No obstante, quizás conviene no perder de vista que, aún a día de hoy, algunas de las preguntas que el propio Forsthoff se planteaba siguen sin respuesta (piénsese, particularmente, en el ámbito material de las prestaciones de Daseinsvorsorge: ¿qué debemos considerar servicio público y qué no?), poniendo de relieve la dificultad de tales debates ya en ese momento inicial.

De lo que, en cualquier caso, no cabe dudar es de que Forsthoff ocupó un lugar destacado en la construcción del Derecho administrativo alemán de la República federal de Bonn, y de que el concepto de Daseinsvorsorge ha sido un concepto crucial -incluso revolucionario- para la evolución del Derecho de los servicios públicos en Alemania hasta el momento presente.

Como ha señalado Esteve Pardo, la explosión de ideas que se produjo en Weimar y durante el periodo de entreguerras en Europa ( $y$ no hay duda de que en esa explosión de ideas hay que situar el germen de la Daseinsvorsorge) marcó decisivamente el Derecho administrativo: "el que llegó al inicio de ese periodo era el que se había estado gestando en el siglo XIX, y el que se vislumbra al final de él responde a nuevos postulados y exigencias" ${ }^{82}$, muchas de las cuales llegan hasta la actualidad. Entre ellas, ocupa un lugar destacado la Administración prestacional y las prestaciones de procura existencial.

\section{BIBLIOGRAFÍA}

AAVV, "Aussprache und Schlussworte", en AAVV, Die deutsche Staatsrechtslehre in der Zeit des Nationalsozialismus, Veröffentlichungen der Vereinigung der Deutschen Staatsrechtslehrer núm. 60, Walter de Gruyter, Berlín-Nueva York, 2001, pp. 106-147.

BULLINGER, Martin, "El service publique francés y la Daseinvorsorge alemana", Revista de Administración Pública núm. 166, 2005, pp. 29-49.

82 José ESTEVE PARDO, El pensamiento antiparlamentario y la formación del Derecho público en Europa, op. cit., p. 161. 
CALDWELL, Peter, "Ernst Forsthoff and the legacy of radical conservative State Theory in the Federal Republic of Germany", History of Political thought, vol XV, núm. 4, 1994, pp. 615-641.

DOEHRING, Karl, "Ernst Forsthoff", en AAVV, Juristen im Portrait. Verlag und Autoren in 4 Jahrzenten: Festschrift zum 225 Jährigen Jubiläum des Verlages, C. H. Beck, Múnich, 1988, pp. 341-349.

—, "Enrst Forsthoff als Hochschullerhrer, Kollege und Freund", en Willi BLÜMEL (ed.) Ernst Forsthoff: Kolloquium aus Anlass des 100. Geburtstags von Prof. Dr. H.c. Ernst Forsthoff, Wissenschaftliche Abhandlungen und Reden zur Philosophie, Politik und Gesitesgeschichte, Band 30, Duncker \& Humblot, Berlin, 2003, pp. 9-20.

DREIER, Horst, "Die deutsche Staatsrechtslehre in der Zeit des Nationalsozialismus", en AAVV, Die deutsche Staatsrechtslehre in der Zeit des Nationalsozialismus, Veröffentlichungen der Vereinigung der Deutschen Staatsrechtslehrer núm. 60, Walter de Gruyter, Berlín-Nueva York, 2001, pp. 9-69.

DUGUIT, Léon, Las transformaciones del Derecho Público, Imprenta F. Beltrán, Madrid, 1926 (traducción con estudio preliminar de Adolfo Posada y Ramón Jaén).

ESTEVE PARDO, José, El pensamiento antiparlamentario y la formación del Derecho público en Europa, Marcial Pons, Madrid-Barcelona-Buenos Aires-Sao Paulo, 2019.

FORSTHOFF, Ernst, "Die Daseinsvorsorge als Aufgabe der modernen Verwaltung", en Ernst FORSTHOFF, Rechtsfragen der leistenden Verwaltung, W. Kohlhammer Verlag, Stuttgart, 1959 [1938], pp. 22-34.

—, "Folgerungen", en Ernst FORSTHOFF, Rechtsfragen der leistenden Verwaltung, W. Kohlhammer Verlag, Stuttgart, 1959 [1938], pp. 35-46.

—, Tratado de Derecho administrativo, Instituto de Estudios Políticos, Madrid, 1958.

-, "Vorwort", en Ernst Forsthoff, Rechtsfragen der leistenden Verwaltung, W. Kohlhammer Verlag, Stuttgart, 1959.

-, "Einleitung", en Ernst Forsthoff, Rechtsfragen der leistenden Verwaltung, W. Kohlhammer Verlag, Stuttgart, 1959 [1938], pp. 9-21.

—, "Anrecht und Aufgabe einer Verwaltungslehre", en Ernst FORSTHOFF, Rechtsfragen der leistenden Verwaltung, W. Kohlhammer Verlag, Stuttgart, 1959, pp. 47-63.

-, "Sentido actual de las relaciones entre Estado y sociedad en Alemania", en Ernst FORSTHOFF, Problemas actuales del Estado social de Derecho en Alemania, Publicaciones del Centro de Formación y perfeccionamiento de Funcionarios, Madrid, 1966, pp. 13-35.

-, "Trasformazioni strutturali della democrazia moderna" (1964), en Alessandro Mangia, L'ultimo Forsthoff. Scritti 1961/1969 di E. Forsthoff su Costituzione ed amministrazione tradotti e commentati, Cedam, Milán, 1995 [1963].

—, "Problemas constitucionales del Estado Social" en Ernst FORSTHOFF/Wolfgang ABENDROTH/ Karl DOEHRING, El Estado Social, Centro de Estudios Constitucionales, Madrid, 1986 [1963], pp. 43-69.

HÄBERLE, Peter, "Lebende Verwaltung trotz überlebter Verfassung? Zum wissenschaftlichen Werk von Ernst Forsthoff”, en Peter HÄBERLE, Beiträge zur Staatsrechtslehre und Verfassungskultur, Duncker \& Humblot, Berlín, 2002, pp. 3-15.

KERSTEN, Jens, "Die Entwiklung des Konzepts der Daseinsvorsorge im Werk von Enst Forsthoff", Der Staat, vol. 44, núm. 4, 2005 , pp. 543-569.

KLEIN, Hans Hugo, "Der totale Staat. Betrachtungen zu Ernst Forsthoffs gleichnamiger Schrift von 1933”, en Willi BLÜMEL, (ed.), Ernst Forsthoff: Kolloquium aus Anlass des 100. Geburtstags von Prof. Dr. H.c. Ernst Forsthoff, Wissenschaftliche Abhandlungen und Reden zur Philosophie, Politik und Gesitesgeschichte, Band 30, Duncker \& Humblot, Berlín, 2003, pp. 21-39.

LAAK, Dirk van, Gespräche in der Sicherheit des Schwiegens. Carl Schmitt in der politischen Geistegeschichte der frühen Bundesrepublik, Akademie Verlag, Berlín, 1993.

MAGALDI, Nuria, Procura existencial, Estado de Derecho y Estado Social, Serie de teoría jurídica y filosofía del derecho núm. 48, Universidad Externado, Bogotá, 2007.

- Los origenes de la municipalización de servicios en España, Instituto Nacional de Administración Pública, Madrid, 2012. 
MALARET I GARCIA, Elisenda, "Servicios públicos, funciones públicas, garantía de los derechos de los ciudadanos: perennidad de las necesidades, transformación del contexto", Revista de Administración Pública, núm. 145 (1998), pp. 49-88.

MANGIA, Alessandro, "Introduzione", en Alessandro MANGIA, L 'ultimo Forsthoff. Scritti 1961/1969 di E.Forsthoff su Costituzione ed amministrazione tradotti e commentati, Cedam, Milán, 1995, pp. 3-38.

MANGIA, Alessandro, L'ultimo Forsthoff. Scritti 1961/1969 di E. Forsthoff su Costituzione ed amministrazione tradotti e commentati, Cedam, Milán, 1995.

MARTÍN-RETORTILLO, Lorenzo, "La configuración jurídica de la Administración pública y el concepto de Daseinsvorsorge", Revista de Administración Pública núm. 38, 1962, pp. 35-65.

MAURER, Hartmut, Allgemeines Verwaltungsrecht (17. a ed.), Verlag C. H. Beck, Munich, 2009.

- Derecho Administrativo. Parte General (traducción coordinada por Gabriel DOMÉNECH PASCUAL), Marcial Pons, Madrid-Barcelona-Buenos Aires, 2011.

MEINEL, Florian, "Review Essay -Ernst Forsthoff and the intellectual History of German Administrative Law", German Law Journal, vol. 8, núm. 8, 2007, pp. 785-800.

PAULY, Wolfgang, "Die deutsche Staatsrechtslehre in der Zeit des Nationalsozialismus", en AAVV, Die deutsche Staatsrechtslehre in der Zeit des Nationalsozialismus, Veröffentlichungen der Vereinigung der Deutschen Staatsrechtslehrer núm. 60, Walter de Gruyter, Berlín-Nueva York, 2001, pp. 73-101.

POSADA, Adolfo, "La ciudad moderna", en Adolfo Posada, Escritos municipalistas de la vida local, Instituto de Administración Pública, Madrid, 1979 [1913], pp. 317-409.

REINTHAL, Angela/ MUSSGNUG, Reinhard/ MUSSGNUG, Dorothee (ed.), Briefwechsel Ernst Forsthoff-Carl Schmitt (1926-1974), Akademie Verlag, Berlín, 2007.

SCHEIDEMANN, Dieter, Der Begriff Daseinsvorsorge: Ursprung, Funktion und Wandlungen der Konzeption E. Forsthoffs, Muster-Schmidt, Göttingen, 1991.

SCHNEIDER, Hans, "Ernst Forsthoff. Berichte”, Die Öffentliche Verwaltung núm. 17, 1974, pp. $596-$ 597.

SCHÜTTE, Christian, Progressive Verwaltungsrechtswissenschaft auf konservativer Grundlage: Zur Verwaltunsrechtslehre Ernst Forsthoffs, Dunker \& Humblot, Berlín, 2006.

SORDI, Bernardo, "Il primo e l'ultimo Forsthoff", Quaderni fiorentini, núm. 25, Giuffrè, Milán, 1996, pp. 667-682.

SOSA WAGNER, Francisco, Carl Schmitt y Ernst Forsthoff: coincidencias y confidencias, Marcial Pons, Madrid-Barcelona-Buenos Aires, 2008.

STOLLEIS, Michael, Geschichte des Öffentlichen Rechts in Deutschand, Dritter Band 1914-1945, C. H. Beck, Múnich, 1999.

RONELLENTITSCH, Michael, "Daseinsvorsorge als Rechtsbegriff. Aktuelle Entwicklungen im nationalen und europäischen Recht" en Willi BLÜMEL (ed.) Ernst Forsthoff: Kolloquium aus Anlass des 100. Geburtstags von Prof. Dr. H.c. Ernst Forsthoff, Wissenschaftliche Abhandlungen und Reden zur Philosophie, Politik und Gesitesgeschichte, Band 30, Duncker \& Humblot, Berlín, 2003, pp. 53-114. 